\title{
Rolling contact fatigue of surface coatings-a review
}

\author{
S. Stewart, R. Ahmed* \\ Department of Mechanical and Chemical Engineering, Heriot-Watt University, Riccarton, Edinburgh EH14 4AS, UK
}

Received 16 July 2001; received in revised form 18 July 2002; accepted 15 August 2002

\begin{abstract}
The aim of this review is to survey the state of the art relating to the rolling contact fatigue (RCF) investigation of various overlay coatings and also, to ascertain the influence of design parameters such as the type of deposition process, coating material and thickness on the RCF performance. Rolling contact fatigue is a significant factor in the failure of components in rolling/sliding contact. Although, sintered ceramics have provided improvements in RCF life of components in rolling/sliding contact, e.g. hybrid ceramic bearings, the economic and technological constraints associated have so far limited their use to specialist applications. Physical and chemical vapor deposition (PVD, CVD) as well as thermal spraying are methods of depositing overlay coatings. The designer must thus choose a deposition method based on economic and technical flexibility, e.g. material choice, functional grading, etc. Amongst this family of overlay coatings, PVD coatings are already finding commercial use whilst others are at a research and development stage. The available literature on the RCF testing of various types of overlay coatings is considerable, but it is generally difficult to synthesize all of the results to obtain a comprehensive understanding of the parameters which can have a significant effect on a coating's resistance to rolling contact fatigue. This review thus compares the RCF performance of these overlay coatings and discusses the results in terms of coating processes, materials, thickness, residual stress and tribological conditions of contact stress and lubrication.
\end{abstract}

(c) 2002 Elsevier Science B.V. All rights reserved.

Keywords: Rolling contact fatigue; PVD; CVD; Thermal spray

\section{Introduction}

Rolling contact fatigue (RCF) is responsible for the failure of rolling element bearings, gears, camshafts and may be defined as cracking or pitting/delamination limited to the near-surface layer of bodies in rolling/sliding contact. There is an increased demand for improved life, reliability and load bearing capacity of bearing materials and future applications call for their use in more hostile environments. In this literature review, overlay coatings deposited by thermal spray, physical vapor deposition and chemical vapor deposition processes have been investigated in terms of their resistance to various failure mechanisms in rolling sliding contact. Published literature contains information on several coatings, which have been subjected to rolling contact fatigue tests until failure occurred. The microstructures of the coatings have been investigated previously using vari-

Abbreviations: APS, air plasma spray; CVD, chemical vapor deposition; D-Gun, detonation gun; DLC, diamond like carbon; EHL, elasto-hydrodynamic lubrication; FEM, finite element model; HVOF, high velocity oxy-fuel; PACVD, plasma assisted chemical vapor deposition; PVD, physical vapor deposition; RCF, rolling contact fatigue

* Corresponding author. Tel.: +44-131-449-5111; fax: +44-131-451-3129.

E-mail address: R.Ahmed@hw.ac.uk (R. Ahmed). ous types of non-destructive testing techniques. The results from the published information were thus studied to establish the effect of variation in initial coating parameters, such as coating thickness, hardness and material on the coating's resistance to RCF failure. The deposition process and process parameters are also seen to have an important influence and this review addresses the effects of these on the RCF resistance of these overlay coatings.

\subsection{Deposition processes}

Coatings deposited by thermal spraying (TS), physical vapor deposition (PVD) and chemical vapor deposition (CVD) processes are used extensively in industry.

Thermal spray coatings are deposited by a variety of processes such high velocity oxy-fuel (HVOF) and plasma spray. HVOF coatings exhibit limited porosity and contain minimal microstructural defects and are thus used in applications for resistance against wear, erosion, oxidation and corrosion, etc. Plasma spray coatings are deposited by a much higher heat source thus depositing coatings with good thermal barrier properties. They are hence used in the aerospace industry.

PVD coatings were developed in 1852 by Faraday [1] and the process encompasses three different techniques: 
evaporation, sputtering and ion plating. In order to control residual stresses, coating thickness is seldom seen in excess of a few microns. In terms of industrial applications, blades are coated with PVD coatings in order to extend their life in the gas turbine industry whilst in tool making applications, TiN coatings have been deposited using the PVD techniques onto high speed cutting tools and punches in order to improve their wear resistance.

CVD coatings were not introduced until the 1950s and involved the deposition of a solid material from the vapor phase onto a heated substrate as a result of a set of chemical reactions. In order to enhance the process a gas plasma was incorporated. This enabled improved control of the residual stresses within the coating, thereby allowing the possibility of relatively thicker coatings to be incorporated at a higher deposition rate.

\subsection{RCF test methods employed for overlay coatings}

The roller type RCF testing machine, i.e. two- and threeroller types, is one of the most widely used machines to evaluate the rolling contact fatigue performance of overlay coatings. Failure is defined as the increase in the vibration amplitude which follows the formation of spall/delamination or a pit. This increase in vibration is measured by sensors which relay signals back to a computer and this results in the termination of the test. These machines have the ability to incorporate sliding within the rolling contact region and are suitable for simulating the rolling/sliding line contact configurations, e.g. for gear and cam/tappet applications. In addition to the roller type machines, overlay coatings have also been tested in pure rolling conditions using either a modified four-ball machine [2] or a ball-on-rod machine [3]. These machines are capable of simulating the kinematics of rolling bearings and can provide point contact configuration. The test machine can however, have an influence on the RCF performance [4] thereby iterating the need for full scale testing. The results compared in this literature are therefore, qualitative to benchmark various overlay coatings using model contact configurations prior to full scale testing.

\section{RCF performance of thermal spray coatings}

Table 1 summarises the typical RCF test results from the published literature. These results are presented in terms of deposition process, coating hardness, thickness and tribological test conditions of contact stress, configuration and lubrication. The following sections aim to analyse these results in terms of these parameters.

\subsection{Effect of variation in deposition process}

The process of thermal spraying can result in coatings with discontinuities such as pores, thermal stress induced cracks, oxide lamellas or incompletely molten particles.
The structural features of the coating are therefore highly dependent on the spray processes and parameters involved during spraying [5-8]. Various researchers $[9,10]$ have investigated the influence of deposition process on the RCF life of thermal spray coatings. In the experimental testing by Nieminen et al. [9], WC-Co coatings were deposited using both HVOF and APS spraying techniques. In depositing the coatings using the APS technique, decarburization of WC followed by the formation of undesirable carbides such as $\mathrm{W}_{2} \mathrm{C}$ and complex $\mathrm{Co}-\mathrm{W}-\mathrm{C}$ phases occurred. This was due to the high temperature of the plasma flame and the oxidising spray temperature. The HVOF spray process however, has a lower flame temperature and a significantly higher particle velocity. The microstructure of the coatings deposited using the HVOF technique was thus considerably different. Less phase transformations into the starting material were induced and a denser coating was produced with lower porosity and higher cohesive strength. It has also been observed that the improved wear resistance was achieved when there was a high percentage of retained WC in the coating. The rolling contact fatigue testing of these coatings deposited using the two different deposition techniques was carried out using a two-roller configuration in pure rolling dry conditions. It was concluded that the improved microstructure of HVOF coatings led to higher fracture toughness and less proportion of secondary phase particles giving superior RCF performance in comparison with APS coatings. Makela et al. [10] has also compared the performance of D-Gun and HVOF WC-12\%Co coatings using a two and three roller test machine in dry rolling/sliding conditions. However, the results were inconclusive to ascertain the influence of spray deposition process. Ahmed and Hadfield [2,11-13] compared the performance of WC-12\%Co coatings produced by D-Gun, APS and $\mathrm{HVOF}$ processes and results were consistent with the findings that, HVOF coating due to its improved microstructure and fracture toughness shows relatively improved RCF performance.

Apart from influencing the RCF performance, the spraying method also altered the failure mechanisms of thermal spray coatings. From XRD analysis and optical micrographs it was observed that the pit formation on the surface of the plasma sprayed coating was more intensive and uniform, when compared with the HVOF sprayed coatings. These pits were the origin of the RCF damage since the high contact load induced cracks at the edges of the pits and this led to the spalling of the surface. The surfaces of the HVOF coatings were practically free of initial pits with only a few isolated pits being observed on the surface of the coatings. This was related to the high particle velocity and low flame temperature of the HVOF spray process, which resulted in a superior coating microstructure and thus improved RCF performance.

With the HVOF coatings, there were two distinctly different RCF failure modes. The RCF failure was initiated by the formation of surface cracks perpendicular to the 


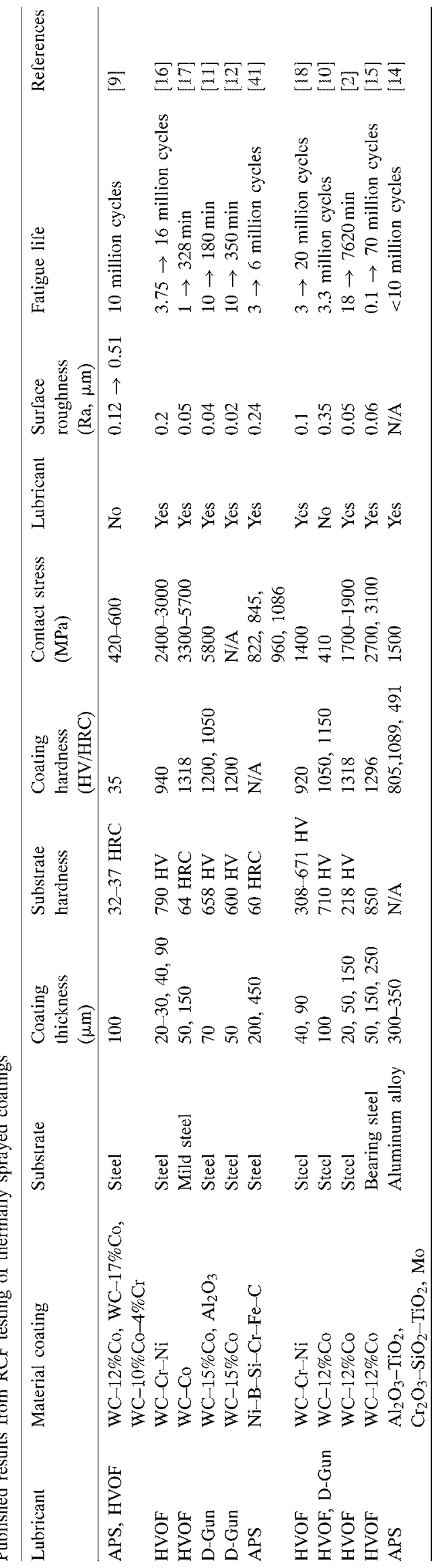


rolling direction. Failure then proceeded with spallation of small pieces of coating from the edges of the cracks. The other mode of RCF failure was initiated by the formation of shallow pits on the coating surface. With increased contact load, these shallow pits propagated with the spallation of small pieces of coating from the edges of the pits. The main difference in RCF failure between the coatings formed by different spraying processes was that after RCF testing, APS coatings displayed increased surface roughness, whereas the HVOF coating's surface roughness remained constant during RCF testing. It was concluded that the superior RCF performance of the HVOF coatings was due to the high particle velocity and low flame temperature associated with this spray process. The HVOF process produced coatings with a dense microstructure and high cohesive strength with a low amount of detrimental brittle phases in the microstructure. These coating characteristics were advantageous in resisting RCF failure.

\subsection{Effect of variation in the coating material}

In the experimental work by Tobe et al. [14], the rolling contact fatigue resistance of two kinds of thermal sprayed ceramic coatings and one thermally sprayed metal coating were tested using a two-roller type testing machine. The thickness of the coatings was kept constant. From the RCF tests, it was observed that the metal coating had the highest rolling fatigue strength. This was related back to residual stresses. After RCF testing there was significantly greater compressive residual stresses in the metal coating than in the ceramic coatings.

A number of blisters formed on the surface of the failed thermal spray coatings which led to coating delamination. These blisters were generated between the coating and substrate. During RCF testing, the coatings plastically deformed. This plastic deformation generated shear stresses between the coating and the substrate. If the shear stress was greater than the shear strength between the coating and substrate then blisters formed on the surface of the coating. Since the compressive strength of the metal coating was greater than the thermal spray coating a higher rolling fatigue strength was exhibited by the metal coating.

In another experimental analysis, Nieminen et al. [9] investigated the rolling contact fatigue resistance of thermally sprayed WC-Co coatings of differing compositions using a two-roller configuration in unlubricated and pure rolling conditions. One main objective of the experimental analysis was to compare the influence of the coating composition (WC-12\% Co, $\mathrm{WC}-17 \% \mathrm{Co}$, and $\mathrm{WC}-10 \% \mathrm{Co}-4 \% \mathrm{Cr}$ ) on the RCF behaviour. The XRD analysis of the coatings indicated $\mathrm{WC}$ as the main constituent and varying percentages of other phases such as $\mathrm{W}_{2} \mathrm{C}, \mathrm{W}$ and $\mathrm{Co}-\mathrm{W}-\mathrm{C}$ carbides. The mixed carbides had the greatest effect on the mechanical properties of the overall coating, since they existed as poorly crystallized phases. These phases were regarded as binder consuming and increased the brittleness of the coating microstructure due to the decrease of the metallic binder. It was concluded that for WC-Co coatings to have good RCF resistance, high microhardness and uniform carbide distribution in the dense microstructure combined with a low amount of detrimental phases was required.

In the experimental analysis by Ahmed and Hadfield [11], WC-Co and $\mathrm{Al}_{2} \mathrm{O}_{3}$ were tested for resistance against rolling contact fatigue using a modified four-ball machine. WC-Co coatings performed better than the $\mathrm{Al}_{2} \mathrm{O}_{3}$ coatings. Using a SEM, the surface of a failed WC-Co coating was analysed. The $\mathrm{Al}_{2} \mathrm{O}_{3}$ coating failed before any significant wear track was formed. This indicated that the failure of the coating was much more dependent on sub-surface effects rather than surface effects. Contrary to this, in WC-Co coatings, the fatigue failure occurred within the WC-Co coating material. When the coatings delaminated at the substrate interface, the failure occurred due to poor adhesive strength as a result of thermal and mechanical mismatch between the coating and substrate. The RCF performance was poorer for ceramic coatings when compared with cermet coatings. Comparing these results $[11,9,14]$ indicated that cermet coatings performed better than ceramic which in turn were better than metallic coatings. Similarly, the failure mechanism for cermet was generally adhesive or cohesive delamination, whereas ceramic and metallic coatings failed by interfacial delamination-though the mechanism leading to such failure varied.

\subsection{Effect of variation in coating thickness}

The coating thickness has been shown to be an important parameter in the rolling contact fatigue resistance of thermally sprayed coatings [15-18]. Investigations indicate that the increase in coating thickness was beneficial in improving the RCF life of thermal spray coatings. Ahmed and Hadfield [13] further concluded that the increase in coating thickness also altered the subsurface stress distribution and thus caused the delamination behaviour to change from interfacial (adhesive) delamination to cohesive delamination. This change in delamination behaviour also holds the key in understanding the reason for improved performance of relatively thicker coatings. As the coating thickness increases, shear stresses shift away from the coating substrate interface. Since the interface represents the weakest section in the coating substrate system, it is subjected to a lower stress due to the increase in coating thickness, thereby resulting in improved RCF performance.

\subsection{Effect of residual stress}

Residual stress in the thermal spray coating is another factor that controls their RCF performance. The reason for the coating process having an effect on the residual stresses within the coating can be understood from the coating's microstructure. During thermal spraying, each molten lamella lands on an already solidified lamella or substrate. This 
generates microstresses, which are of a tensile nature within the individual splats [19] and are also referred as quenching stresses. These microstresses are generated at the interface of the lamellas and at the coating substrate interface. The difference in coefficient of thermal expansion between the coating and the substrate also creates residual macro stresses in the coating and substrate materials. This occurs as a result of the thermal spraying process, whereby as the substrate temperature increases, the temperature of the deposited lamellas decreases due to heat conduction into the substrate. The anisotropy of thermally sprayed coatings also has an effect on the magnitude and orientation of the residual stresses within the coating.

With respect to the type of thermal spraying process, it has been found that stress induced in the coating, as a result of deposition by the plasma spray process, is of a tensile nature where as D-Gun coatings produce compressive stresses in the coatings [20]. It has also been found that the magnitude of residual stresses in coatings increases with an increase in coating thickness [21]. In the experimental analysis of thermal spray coatings being tested for resistance against rolling contact fatigue by Ahmed and Hadfield [17], residual stress fields were measured in three different directions. This enabled the investigation of the effect of measurement direction on the residual stress results [21]. It was concluded that the magnitude of compressive residual stress within the coating attenuated during RCF testing due to the deformation and microcracking that occurred in the coating during rolling contact. Also, due to the anisotropy of the coating, the residual stress values changed depending on the substrate geometry and direction of residual stress measurement.

In another study, aluminum alloy substrates of high strength were thermally sprayed using the plasma technique with ceramic and metal coatings [14]. A two-roller type RCF testing machine was used to investigate the rolling contact fatigue resistance of the coatings. Residual stresses measured in the coatings before RCF tests, using the X-ray diffraction technique, were very low. This was because the high residual stress that formed during thermal spraying was relieved by crack formation during cooling. However, after RCF tests, higher residual compressive stresses were measured in the ceramic and metal coatings. In comparing the residual stress values for these coatings, it was observed that the residual stress levels in the metal coatings were high which indicated plastic deformation under Hertzian loading. This led to metallic coatings displaying increased resistance to RCF failure. The increase in compressive residual stress levels in the ceramic coatings however, was relatively low and this was associated with lower fatigue strength. This change in residual stress also provides some insight to the surface initiated failure mechanism. As the residual stress measurements using X-ray diffraction are very near the surface, the increase in stress level during RCF in metal coatings can be associated with the material shakedown effect. For metallic coatings, this indicates plastic deformation of the near-surface layer. However, for harder and brittle coat- ing materials such as WC-Co, microcracking of the material is generally observed which attenuates the level of compressive stress [17] rather than increasing the magnitude of compressive residual stress. Hence the magnitude of residual stress prior to RCF testing and a change in its magnitude during the RCF test can not only provide feed back on the useful life of the coating, but also its failure mechanism.

\subsection{Effect of lubrication}

In the majority of the published literature, an important variation in the experimental analysis was the influence of lubricant. It was therefore important to investigate whether lubrication had an effect on the rolling contact fatigue strength of thermally sprayed coatings.

In the rolling contact fatigue testing of thermally sprayed coatings using a modified four-ball machine by Ahmed and Hadfield [2], the wear of thermally sprayed WC-Co was investigated in rolling contact under various tribological conditions of lubrication and contact configuration. The lubricants were varied to provide fully developed $(\lambda>3)$, mixed $(\lambda>1)$, and boundary regimes $(\lambda<1)$, where $\lambda$ is the ratio of fluid film thickness to average surface roughness. From the test results, it was indicated that the lubrication regime could have a significant effect on the RCF performance of these coatings. The results from RCF testing indicated that coatings performed better with the high viscosity lubricant $(\lambda>3)$. Apart from influencing the RCF performance of overlay coatings, the lubricant film significantly affected the failure mechanism. In the absence of any lubricant, e.g. in studies by Makela et al. [10], it was noted during RCF testing that local stress concentrations were occurring in the coatings. They were caused by microgeometrical unconformity of the contacting surfaces. Since the coatings being tested were high hardness cermet coatings, these stress concentrations could not be overcome by plastic deformation and instead remained at high stress levels during testing, since no lubricant was available to share the asperity load, which eventually led to poor RCF performance.

\section{RCF performance of PVD coatings}

Table 2 summarises the RCF performance results for various PVD coatings. The coating material deposited by PVD technique studied in the majority of the published information was either titanium or carbon based (diamond like carbon, DLC). All other types of material coatings studied were assumed to have similar mechanical properties. The most important factors controlling the RCF life and failure mechanism of PVD coatings were coating material, thickness and residual stress as discussed below.

\subsection{Influence of coating material and thickness}

In the work by Carvalho et al. [22], where TiN was ion plated onto tool steel substrates, the coatings were subjected 


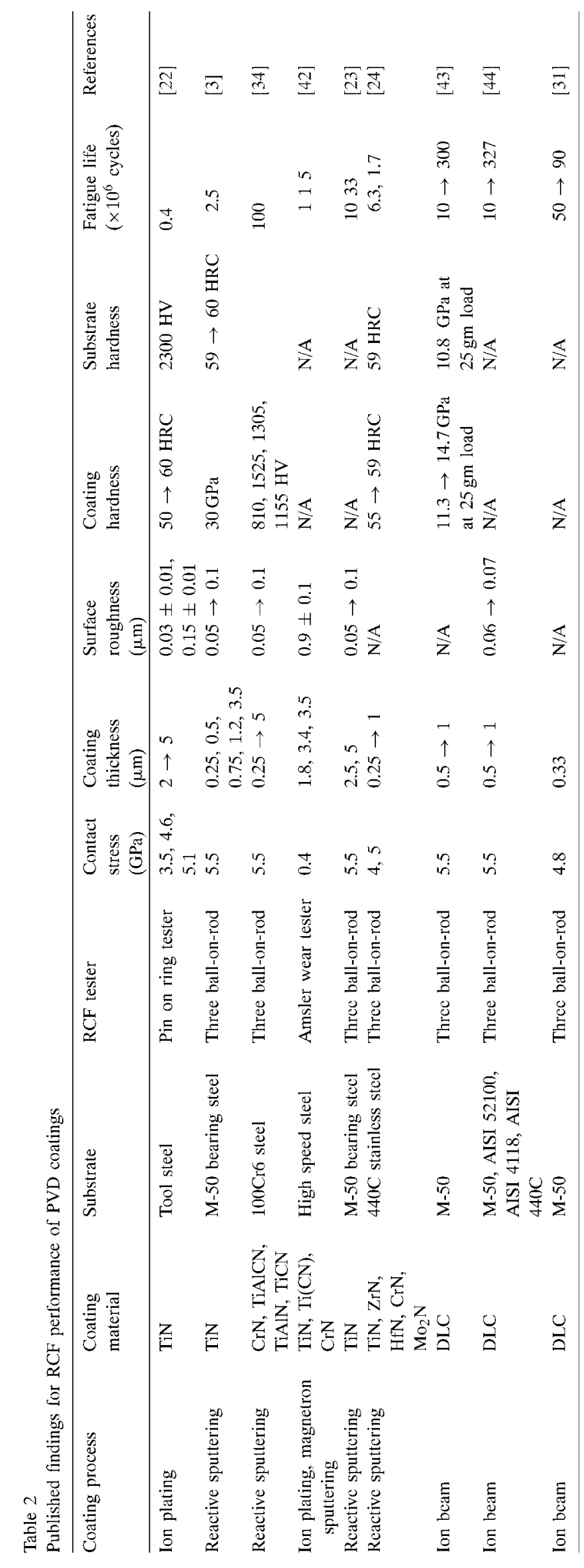


to a range of contact stress levels. It was seen that at lower stress levels, the pre-treatment and the surface roughness of the coatings had a significant influence on the fatigue life. However, at high contact stresses, there was little influence from these two parameters. In isolating the fatigue pits which formed as a result of RCF testing, it was noted that the number of fatigue pits usually increased with decreasing stress levels. This was however, only noted with a low hardness of coating. An increase in the coating hardness had an opposite effect. This was mainly because, with increasing stress levels, the amount and size of failure spots also increased. These pits were initiated by cracks at the interface, which grew in the coating parallel to the surface. Therefore, the interfacial failure stress was closely associated with the coating substrate boundary conditions.

The rolling contact fatigue of titanium nitride was also studied by Polonsky et al. [3]. The coatings were applied using a different physical vapor deposition technique (reactive sputtering), onto M-50 bearing steel rods. The rolling contact fatigue tests were carried out using a "three ball-on-rod" test method. However, in this work, the contact stress was kept constant, as the aim of the experimental analysis was to see what the effect the coating thickness had on the RCF life of the coating. On increasing the coating thickness, it was seen from Weibull plots that the L50 life was greatly enhanced. This pattern continued until the coating thickness was increased to $1 \mu \mathrm{m}$, at which point the RCF life declined.

Two progressive RCF tests were then carried out on $3 \mu \mathrm{m}$ coated substrates. The test terminated on the formation of a macroscopic spall in the rolling track. From the examination of the rolling track using optical microscopy, it was found that the origin of the terminal fatigue spall could be traced to a coating damage patch, however there was no evidence that any of the macroscopic fatigue spalls had been triggered by a micropit. In the experimental analysis by Carvalho et al. [22], it was stated that the macroscopic fatigue spalls were initiated by cracks at the interface. However, SEM images by Polonsky et al. [3] showed that the damage patches were produced by localised exfoliation of upper coating layers rather than debonding along the interface. TiN coatings are known for their excellent bonding to steel substrates [23-25], therefore the failure was concluded to be cohesive rather than adhesive. In carrying out progressive RCF tests with thickness of 0.5 and $0.25 \mu \mathrm{m}$, no damage patches were seen using optical microscopy. It was therefore, assumed that the presence of large defects was the reason for the inability of thick coatings to withstand high magnitude contact stress. The work by Carvalho et al. and Polonsky et al. therefore, contradicted one another in the reason for the damage patches forming on the surface of the coating. It is more likely however, that in fact there was more than one reason for the damage patches forming and also two kinds of RCF failure occurring; subsurface initiated RCF and near-surface initiated RCF [26,27]. Subsurface initiated RCF is where fatigue crack initiation is caused by shear stresses generated by macroscopic contact and usually occurs in the subsurface region. Near-surface
$\mathrm{RCF}$ however, is where fatigue initiation is caused by small scale contact stress perturbations generated by surface roughness or by small abrasive particles that may be present in the lubricants, and occurs in near-surface material layers.

Several different theories have been put forward on what effect the thickness of the coating had on the rolling contact fatigue of the coating. In the previous tests $[3,22]$, the RCF investigations were performed using the same type of tester. However, in the tests by Cheng et al. [28], TiN coatings were tested using a two-disc machine. The results from this test indicated that relatively thick coatings could not protect the substrate material, whereas the thin coatings improved the rolling contact fatigue life of the specimens. The optimum coating thickness for the TiN coatings was considered as $0.25 \mu \mathrm{m}$. These results were substantiated by Thom et al. [29], who tested titanium nitride coatings under similar conditions. The results from these tests indicated that the optimum coating thickness was in the range of $0.5 \mu \mathrm{m}$. It was also concluded from these tests that TiN coatings failed adhesively while $\mathrm{CrN}$ coatings failed cohesively. The difference in failure mechanism also resulted in $\mathrm{CrN}$ coatings outperforming TiN coatings. In all the experiments titanium based coatings disappeared from the wear tracks at the end of the tests. However, the $\mathrm{CrN}$ coatings were only slightly worn within the tracks. Some pitting was also detectable as chromium and nitrogen were detected in the pitting. For this reason, $\mathrm{CrN}$ was concluded to fail cohesively [30].

DLC coatings deposited by ion beam method also indicate similar properties in terms of coating thickness with a magnitude of around $0.75 \mu \mathrm{m}$ for optimum RCF performance. These coatings however, have shown improved RCF life (in excess of $300 \times 10^{6}$ stress cycles) in comparison to any other coating considered in the published literature. In some cases however, an interfacial layer of $\mathrm{SiC}$ is needed for improved coating adhesion on steel substrates. Nevertheless, the high hardness (30-60 GPa), low coefficient of friction (0.02 in dry argon or nitrogen environment), and extremely high resistance to sliding wear has enabled them to become an integral part of aerospace industry. In addition to their superior RCF performance at room temperature, DLC coatings have also shown improved RCF performance at temperature of about $350^{\circ} \mathrm{F}$ [31], indicating an RCF life of approximately $50 \times 10^{6}$ stress cycles.

\subsection{Mechanisms of PVD coating failure during RCF testing}

There are a number of different explanations why the defects responsible for RCF crack initiation formed in TiN coatings. One recent method for explaining the defects was attempted by Sproul and coworkers [32] who developed a simple conservative model in which the number of parameters, which could be readily assessed, were kept to a minimum. The model was two-dimensional in order to simplify the analysis of surface roughness and stresses produced by 
it. The coating was assumed to be perfectly bonded to the substrate and the EHL film thickness was assumed to be negligibly small. It was also assumed that the coating was homogeneous and strong. From experimental RCF analysis using a three ball-on-rod tester at a Hertzian pressure of $5.5 \mathrm{GPa}, 51$ rods were tested with thickness values ranging from 0.01 to $100 \mu \mathrm{m}$. Using the model, it was observed that TiN coatings with a thickness of $0.75 \mu \mathrm{m}$ did not increase the RCF life even though they remained intact. Instead it was found that in order to protect the TiN coating against near-surface RCF initiation, the coating had to be deposited on a substrate with a very high surface finish. This is because in general, the surface topography of a PVD coating usually reproduces very closely that of the substrate. With respect to coatings thicker than $3 \mu \mathrm{m}$, it was seen using the model and also atomic force microscopy that the reason for failure was due to defects within the coating microstructure. The typical microstructure for TiN coatings is predominantly columnar with columns becoming coarser as more coating is deposited onto the substrate. Although intercolumnar porosity can be reduced by properly choosing the deposition conditions [33], even in a dense, high quality PVD TiN coating, the interfaces between columns are likely to be weak links in the coating structure. The maximum column height is close to the coating thickness; therefore in thick coatings these weak interfaces will be longer. The work by Sproul and coworkers [32] has therefore shown that coatings designed for use in rolling contact fatigue applications must be sufficiently thick, have good adherence and be able to sustain high magnitude cyclic contact stresses without experiencing cohesive failure. In order to make hard coatings truly effective against near-surface rolling contact fatigue, it is therefore necessary to develop thick coatings $(<3 \mu \mathrm{m})$ which are as adherent as good TiN coatings. The coatings must also possess the fine microstructure and associated resistance to cohesive failure under a cyclic contact loading currently found in thin $(<0.75 \mu \mathrm{m})$ PVD TiN coatings.

Despite the superior RCF performance of DLC coatings, their failure mechanism(s) is however, not completely understood at this stage. It is hypothesized that tiny particles of coating spall from the substrate at the early stage of the RCF test. As the coating thickness is very small $(<1 \mu \mathrm{m})$ this initial spallation is unlikely to trigger the increase in vibration amplitude to indicate RCF failure. The improved RCF performance of DLC coatings is thought to be dictated by the role of these spalled coating debris, as they mix in the test lubricant and initiate polishing of surfaces within the contact region (three body abrasion). This polishing effect reduces the asperity loading and thus resists surface crack initiation. This coupled with the lower coefficient of friction of DLC coatings thus prolongs the RCF life. This also explains the reason for improved RCF life of DLC coatings, even in those cases where there was no coating coverage left after the RCF test.

To obtain a better understanding of the mechanism of RCF failure of PVD coatings, a FEM simulation was created by
Bouzakis at al. [34] for a RCF ball-on-rod test using $\mathrm{CrN}$, TiAlCN, TiAlN and TiCN coatings with thickness ranging from 2 to $2.5 \mu \mathrm{m}$. In the FEM simulation the coating material was assumed to be perfectly elastic, homogeneous and isotropic. The substrate material was treated differently in that it was assumed to possess multi-linear kinematic properties according to the Besseling model [35]. The coating and the substrate were assumed to be perfectly bonded together, so interfacial sliding was not accounted for. From the stress distributions of the FEM model, it was seen that for coating substrate compounds which showed poor adherence during the PVD process, the most critical stress component was the shear stress which developed along the coating substrate interface. It was also found that with thin hard coatings, the determinant factor that influenced the deformation of the coating was the behavior of the substrate.

\subsection{The effect of residual stress on RCF performance of $P V D$ coatings}

Another important parameter that can have an effect on the fatigue life of both CVD and PVD coatings is the residual stresses that form in the coating during the deposition process. With PVD coatings it has been observed that, in general, the residual stress within these coatings is normally compressive and that this compressive stress contributes greatly to the improvement in RCF life, but only up to a certain coating thickness. In coatings of thickness less than $1 \mu \mathrm{m}$, the compressive residual stress prevents cracks from nucleating and propagating. However, once the coating had exceeded $1 \mu \mathrm{m}$, it did not perform as well. This was because the combined stress from the load and the residual stress caused the coating to spall and the wear was accelerated with the abrasive particles in the system. In the experimental analysis by Spies et al. [36], steel samples underwent a plasma nitriding operation before being coated with TiN using the ion plating process. RCF testing was performed using a double disc-testing machine. The results from RCF testing indicated that the higher fatigue limit of nitrided steels was a result of the increase of the hardness and the formation of compressive residual stresses in the hardened case. Thus, it was seen that the thickness and the type of coating have an effect on the extent to which the residual stresses enhance the performance of the coating in RCF testing.

\section{RCF performance of CVD coatings}

\subsection{Influence of coating material and thickness}

The experimental results from the associated literature are summarised in Table 3. In the work by Bai and coworkers [37], TiN was deposited onto high-speed steel substrates using a PACVD coating technique. The thickness of the coatings ranged from 3 to $4 \mu \mathrm{m}$. Silicon was also introduced into the coating as it already has been established 


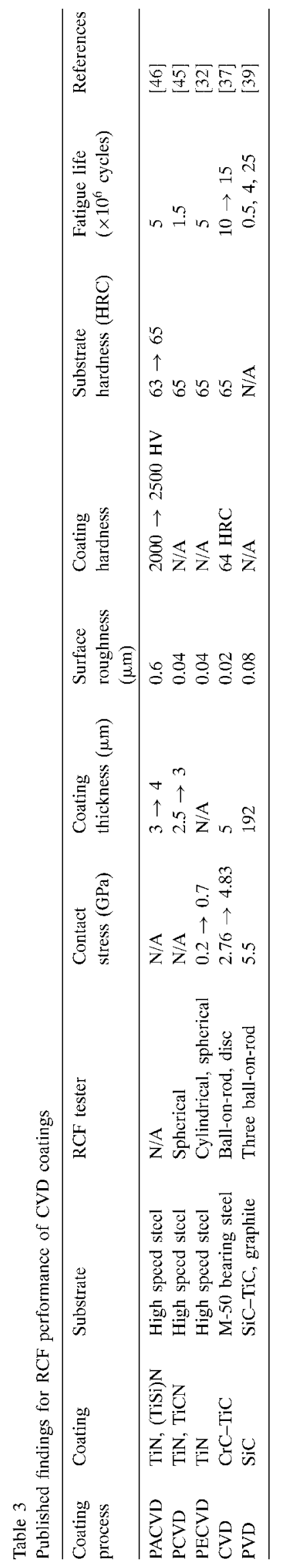


that it improves the oxidation resistance of the coating. In terms of mechanical properties, it is however known that the introduction of silicon into the coating can result in the embrittlement of the TiN film, and therefore decrease its bonding strength. From SEM analysis, it was observed that the PACVD process deposited a coating with a well developed columnar structure, however the replacement of some of the $\mathrm{Ti}$ atoms by $\mathrm{Si}$ atoms has been seen to disturb the smooth growth of the columns. In terms of mechanical properties with increasing Si content, the microhardness of the coating also increased linearly. The rolling contact fatigue of the coatings was tested using an Amsler wear machine. It was therefore concluded that with increasing silicon content, the coating's resistance to rolling contact fatigue improved.

In another experiment, the PCVD technique was used to coat steel substrates with TiN and TiCN [38]. The thickness of the coatings was varied between 1 and $4.2 \mu \mathrm{m}$. A spherical rolling test was used to study the coatings resistance to RCF. The experimental results indicated that TiCN bonded better with the substrate than the TiN. The higher bonding strength of the TiCN coating was not related to its higher hardness but instead due to its good compatibility with the carbides in the substrate.

It was also important to study the adherence of coatings deposited using the CVD process. This was the main objective in the study of CrC-TiC coatings [39]. Two different $\mathrm{RCF}$ testers were used in the experimental analysis of the coatings; the disc RCF tester and the ball-rod RCF tester. The thickness of the coatings was about $5 \mu \mathrm{m}$. The results indicated that the coatings exhibited excellent adherence to various types of substrates at loads up to $4.14 \mathrm{GPa}$. At higher loads there was evidence of coating failure and it was thought that this was due to the high hardness and thickness of the coating.

\subsection{The effect of residual stress on RCF performance of CVD coatings}

Silicon carbide has also been deposited onto substrates by chemical vapor deposition [40]. The main aim in this experimental analysis was to determine whether or not the fracture toughness and strength of the coating could be improved by placing the bearing surface in residual compression. In order to study this effect, a ball-on-rod RCF tester was employed. The rods were made of $\mathrm{SiC}-\mathrm{TiC}$ composite and graphite. They were coated with SiC to a thickness of $250 \mu \mathrm{m}$. During the RCF tests, the initial Hertzian contact stresses were set at 5.5 GPa. The Weibull plots created using the data from the RCF tests indicated that rods with the higher surface compression displayed the longer life times. Using SEM analysis, the rods were studied for microstructural defects. The spall, which caused failure in the rod coating from the RCF test, was shaped like a fan. The subsurface defect, which formed the spall, was located at the centre of the fan. The subsurface defect was a weak interface produced by the interrupted growth of the CVD-SiC coating in the form of cone shaped spherically cupped growth regions. Hence, in order to increase further the performance of rolling contact and surface compression of CVD-SiC coatings, strong adhesion of the coating to the substrate and the minimisation of severe defects is required. From the results obtained during the RCF evaluations, it was indicated that the development of surface compression through thermal expansion miss-match was an effective way to toughen an otherwise brittle material. The RCF life was longer and wear resistance was superior for the CVD-SiC surface with the higher surface compression. This was because with an increase in surface compression, the brittle fracture mechanism of wear was suppressed. However, it was also observed that there was an optimum level of residual surface compression because when the surface compression was extremely high $(<180 \mathrm{MPa})$, it was found that the CVD-SiC layer was likely to spontaneously debond at the substrate-coating interface or at a weak interface within the CVD-SiC coating. The optimum range of residual surface compression will therefore depend on the interface strength and the severity of defects within the CVD-SiC coating.

\section{Comparison of RCF performance of PVD, CVD and thermal spray coatings}

In comparing the results of RCF testing from the published literature for PVD, CVD and thermal spray coatings, a number of observations were made as seen in Table 4. In the experimental analysis by Gardos and coworkers [39], CVD coatings of $\mathrm{CrC}-\mathrm{TiC}$ and reactively sputtered TiN coatings were tested for RCF resistance. The results obtained from the RCF tests showed that all of the CVD coatings were capable of withstanding loads up to $3.45 \mathrm{GPa}$ without failure. The reactively sputtered TiN did not spall at 2.76 and $3.45 \mathrm{GPa}$ and two tracks survived high stress cycles with no spalling at $4.14 \mathrm{GPa}$. At higher stress levels of $5.5 \mathrm{GPa}$, the RCF life of SiC CVD coatings was of the order of $25 \times 10^{6}$ stress cycles [40], which is significantly lower than $100 \times 10^{6}$ stress cycles for TiC and DLC PVD coatings at similar stress level [3]. Thermal spray coatings showed a life in excess of $70 \times 10^{6}$ stress cycles without failure but up to a stress level of $2.7 \mathrm{GPa}$. Hence at stress levels in excess of $3 \mathrm{GPa}$, PVD coatings indicate RCF life superior to that of CVD and thermal spray coatings. However, the control of coating thickness uniformity of approximately $0.5-0.75 \mu \mathrm{m}$ throughout the coating layer for mass-producing curved/spherical surfaces have so far limited the use of PVD technology to high stress specialist applications. CVD coatings have similar limitations but have much better flexibility for coating curved surfaces, e.g. using MPCVD coatings. Also, the coating thickness in CVD coatings is orders of magnitude greater than PVD coatings for optimum RCF performance, hence the flexibility in tolerance of coating thickness uniformity is greater. Similarly, the option of functionally grading the PVD or CVD coating to incorporate dry lubricant film such as Mo or graphite near the coating surface makes them 
Table 4

Comparison of PVD, CVD and thermal spray coatings

\begin{tabular}{|c|c|c|c|}
\hline & \multicolumn{3}{|l|}{ Coating process } \\
\hline & PVD & CVD & Thermal spray \\
\hline Thickness $(\mu \mathrm{m})$ & $0.25 \rightarrow 5$ & $2.5 \rightarrow 5$ & $20 \rightarrow 450$ \\
\hline Substrate hardness (HRC) & 60 & 65 & $20 \rightarrow 60$ \\
\hline Coating hardness (HV) & $810 \rightarrow 1525$ & $2000 \rightarrow 2500$ & $491 \rightarrow 1300$ \\
\hline Contact stress $(\mathrm{GPa})$ & $0.4 \rightarrow 5.5$ & $0.2 \rightarrow 7$ & $0.41 \rightarrow 5.8$ \\
\hline Surface roughness $(\mu \mathrm{m})$ & $0.03 \rightarrow 0.1$ & $0.02 \rightarrow 0.6$ & $0.02 \rightarrow 0.35$ \\
\hline Fatigue life (million cycles) & $100 \rightarrow 300^{\mathrm{a}}$ & $0.5 \rightarrow 25^{\mathrm{b}}$ & $3.3 \rightarrow 70^{\mathrm{c}}$ \\
\hline
\end{tabular}

${ }^{a}$ Maximum value at contact stress of $5.5 \mathrm{GPa}$ for TiN or DLC coating of approximate thickness $0.5 \mu \mathrm{m}$ [3,43].

${ }^{\mathrm{b}}$ Maximum value at contact stress of $5.5 \mathrm{GPa}$ for $\mathrm{SiC}-30 \% \mathrm{TiC}$ coating of thickness $190 \mu \mathrm{m} \mathrm{[39].}$

${ }^{\mathrm{c}}$ Maximum value at contact stress of $2.7 \mathrm{GPa}$ for $\mathrm{WC}-12 \%$ Co coating of thickness $250 \mu \mathrm{m}$ [15].

attractive for aerospace applications. However, the economics of both PVD and CVD process have so far hindered their use in mass production of components requiring improved RCF resistance. Thermal spraying can however help bridge this gap in the industrial sector for low stress RCF applications, especially in harsh tribological environments such as the chemical and mining industry. This is mainly because these coatings not only have the capacity to resist RCF failure but are also well known for their excellent resistance to abrasive and corrosive wear. As the optimum coating thickness for improved RCF performance of thermal spray coatings is of the order of several hundred micrometers, substrate properties become less important thereby also providing the possibility of cheaper substrates. This is not the case for PVD coatings where a thin coating of $0.5 \mu \mathrm{m}$ needs to be supported by a hard substrate. The substrate also needs to retain its hardness after the deposition process, e.g. M-50 steel.

\section{Conclusion}

Published findings regarding the rolling contact fatigue testing of thermal spray, PVD and CVD coatings can be summarised to give the following conclusions:

1. In comparing the effect of different thermal spray techniques on the rolling contact fatigue performance of thermally sprayed coatings, it was observed that the HVOF technique deposited coatings with superior RCF performance. This was because HVOF coatings were observed to have a dense microstructure and high cohesive strength combined with a minimum number of detrimental brittle phases.

2. The type of coating material was also seen to be an important parameter in the RCF performance of thermally sprayed coatings. In comparing cermet, ceramic and metal coatings it was observed that the cermet coatings displayed superior RCF performance followed by ceramic and metallic coating, respectively. Thermal and mechanical mismatch between the coating and the sub- strate was also seen to influence the RCF performance of the coating as they control the degree of compressive residual stress.

3. In varying the thickness of the thermally sprayed coating, it was indicated that coatings of thickness greater than $200 \mu \mathrm{m}$ displayed superior RCF performance over thinner coatings. This was attributed to the location of shear stresses in relation to the coating substrate interface.

4. In the rolling contact fatigue testing of PVD coatings, it was indicated that the optimum thickness of TiN and DLC coatings was found to be in the region of $0.75 \mu \mathrm{m}$. On increasing coating thickness past this level, failures occurred in the early stages of RCF test. The reason for this was due to weak interfaces between the columns in the coating microstructure being lengthened with the increase in coating thickness. Two types of failure were detected in PVD coatings. They were subsurface initiated RCF and near-surface initiated RCF. It was also shown that while TiN PVD coatings failed adhesively, $\mathrm{CrN}$ coatings failed cohesively.

5. The rolling contact fatigue resistance of CVD coatings was enhanced by the introduction of silicon in the coating. CVD coatings failed in RCF testing when the coating possessed high hardness and thickness levels. Like PVD coatings, failure occurred due to weaknesses occurring in the coating microstructure. Defects, which formed the spall, were produced by the growth of the coating in the form of cone shaped spherically cupped growth regions. To improve the coating against RCF, it was concluded that strong adhesion of the coating to the substrate accompanied by minimisation of severe defects would be required.

6. In comparing what effect the type of deposition process had on the coating's resistance to rolling contact fatigue, it was found that PVD coatings displayed superior resistance to RCF at room and elevated temperatures, followed by the performance of CVD and thermal spray coatings, respectively.

7. In analysing the effect of residual stresses on PVD coatings, in general a compressive residual stress enhanced the RCF performance of PVD coatings. However, the 
thickness and the composition of the coating had an effect on the extent to which the residual stresses enhanced the RCF performance of the coating. With CVD coatings, it was found that there was an optimum range for the level of compressive residual stress within the coating at which the RCF performance of the coating was enhanced. If the compressive residual stress level was too high then de-bonding between the coating layers would occur.

\section{References}

[1] M. Faraday, Philos. Trans. R. Soc. 147 (1857) 145.

[2] R. Ahmed, M. Hadfield, Wear of high velocity oxy-fuel (HVOF)coated cones in rolling contact, Wear 203/204 (1997) 98-106.

[3] I.A. Polonsky, T.P. Chang, L.M. Keer, W.D. Sproul, A study of rolling contact fatigue of bearing steel coated with physical vapor deposition TiN films: coating response to cyclic contact stress and physical mechanisms underlying coating effect on the fatigue life, Wear 215 (1998) 191-204.

[4] M. Hadfield, T.A. Stolarski, The effect of the test machine on the failure mode in lubricated rolling contact of silicon nitride, Tribol. Int. 28 (6) (1995) 377-382.

[5] K. Kirner, Concerning the metallurgy of tungsten carbides in thermal spraying, Schweissen Schnieden 41 (1989) 583-586.

[6] M.E. Vinayo, F. Kassabji, J. Guyonnet, P. Fauchais, Plasma sprayed WC-Co coatings: influence of spray conditions (atmospheric and low pressure spraying) on the crystal structure, porosity, and hardness, J. Vac. Sci. Technol. A3 (1985) 2483-2489.

[7] J. Nerz, B.A. Kushner, A.J. Rotolico, Relationship between power processing and deposition methods for aircraft grade tungsten carbide-cobalt coatings, in: Proceedings of the Thermal Spraying Conference, Essen, Germany, 29-31 August 1990, pp. 47-51.

[8] M.P. Subrahmanyam, M.P. Srivastava, R. Sivakumar, Characterisation of plasma sprayed WC-Co coatings, Mater. Sci. Eng. 84 (1984) 209-214.

[9] R. Nieminen, P. Vouristo, K. Niemi, T. Mantyla, G. Barbezat, Rolling contact fatigue failure mechanisms in plasma and HVOF sprayed WC-Co coatings, Wear 212 (1997) 66-77.

[10] A. Makela, P. Vouristo, M. Lahdensuo, K. Niemi, T. Mantyla, Rolling contact fatigue testing of thermally sprayed coatings, in: Proceedings of the 7 th International Thermal Spray Conference, Boston, Massachuesetts, 20-24 June 1994, pp. 759-763.

[11] R. Ahmed, M. Hadfield, Rolling contact fatigue performance of detonation gun coated elements, Tribol. Int. 30 (1997) 129-137.

[12] R. Ahmed, M. Hadfield, Rolling contact fatigue behavior of thermally sprayed rolling elements, Surf. coatings Technol. 82 (1996) 176-186.

[13] R. Ahmed, M. Hadfield, Fatigue failure modes of plasma sprayed coatings, Wear 230 (1999) 39-55.

[14] S. Tobe, S. Kodama, H. Misawa, Rolling fatigue behaviour of plasma sprayed coatings on aluminum alloy, in: Proceedings of the National Thermal Spray Conference, Tokoyo, Japan, 1990, pp. 171-178.

[15] R. Ahmed, M. Hadfield, Influence of coating thickness and contact stress on the fatigue failure of HVOF coatings, in: Proceedings of the International Thermal Spray Conference, Singapore, ISBN 0871707373, 2001, pp. 1009-1015.

[16] M. Yoshida, K. Tani, A. Nakahira, A. Nakajima, T. Mawatari, Durability and tribological properties of thermally sprayed WC cermet coatings in rolling/sliding contact, in: Proceedings of ITSC, Kobe, May 1995, 1992, pp. 663-668.

[17] R. Ahmed, M. Hadfield, Experimental measurement of the residual stress field within thermally sprayed rolling elements, Wear 209 (1997) 84-95.

[18] A. Nakajima, T. Mawatari, M. Yoshida, K. Tani, A. Nakahira, Effects of coating thickness and slip ratio on durability of thermally sprayed
WC cermet coatings in rolling/sliding contact, Wear 241 (2000) 166173.

[19] S. Kuroda, T. Fukishima, S. Kitahara, Significance of the quenching stress in the cohesion and adhesion of thermally sprayed coatings, in: Proceedings of the International Thermal Spray Conference, Orlando, OH, 1992, pp. 903-909.

[20] T. Morishita, E. Kuramochi, R.W. Whitfield, S. Tanabe, Coatings with compressive stress, in: Proceedings of the International Thermal Spray Conference, Orlando, OH, 1992, pp. 1001-1004.

[21] O.C. Brandt, Mechanical properties of HVOF coatings, J. Therm. Spraying 4 (1995) 147-152.

[22] N.J.M. Carvalho, A.J. Huis in't Veld, J.T.H. De Hossen, Interfacial fatigue stress in PVD TiN coated tool steels under rolling contact fatigue conditions, Surf. Coatings Technol. 105 (1998) 109-116.

[23] J.F. Dill, M.N. Gardos, H.E. Hintermann, H.J. Boving, Rolling contact fatigue evaluation of hard coated bearing steels, in: Proceedings of the Third International Conference on Solid Lubrication, ASLE, Denver, 1985, pp. 230-241.

[24] T.P. Chang, Tribological Behaviour of Titanium Nitride Coated Rollers, Ph.D. Thesis, Northwestern University, Evanston, IL, 1991.

[25] P.J. Burnett, D.S. Rickerby, The relation between hardness and scratch adhesion, Thin Solid Films 154 (1987) 403-416.

[26] G.R. Millar, L.M. Keer, H.S. Cheng, On the mechanics of fatigue crack growth due to contact loading, Proc. R. Soc. London, Ser. A 397 (1985) 197-209.

[27] T.A. Harris, Rolling Bearing Analysis, 3rd ed., Wiley, New York, 1991, p. 23.

[28] H.S. Cheng, T.P. Chang, W.D. Sproul, A morphological study of contact fatigue of TiN coated rollers, mechanics of coatings, in: Proceedings of the 16th Leeds-Lyon Symposium, Elsevier, 1990, pp. 81-88.

[29] R. Thom, L. Moore, W.D. Sproul, T.P. Chang, Rolling contact fatigue tests of reactively sputtered nitride coatings of Ti, Zr, Hf, Mo, Ti-Al, $\mathrm{Ti}-\mathrm{Zr}$, Ti-Al-V on 440C stainless steel substrates, Surf. Coatings Technol. 62 (1993) 423-427.

[30] O. Knolek, B. Bosserhoff, A. Schrey, T. Leyendecker, O. Lemmer, S. Esser, A new technique for testing the impact load of thin films: the coating impact test, Surf. Coating Technol. 54/55 (1992) 102-107.

[31] L. Rosado, V.K. Jain, H.K. Trivedi, The effect of diamond-like carbon coatings on the rolling fatigue and wear of M-50 steel, Wear 212 (1997) 1-6.

[32] I.A. Polonsky, T.P. Chang, L.M. Keer, W.D. Sproul, An analysis of the effect of hard coatings on near-surface rolling contact fatigue initiation induced by surface roughness, Wear 208 (1997) 204-219.

[33] I. Petrov, L. Hultman, U. Helmerson, J.E. Sundgren, J.E. Greene, Microstructure modification of reactively sputtered TiN films by ion bombardment during growth, Thin Solid Films 169 (1989) 299-314.

[34] K.D. Bouzakis, N. Vidakis, Prediction of the fatigue behavior of physically vapor deposited coatings in the ball-on-rod rolling contact fatigue test, using an elastic-plastic finite elements method simulation, Wear 206 (1997) 197-203.

[35] ANSYS User Manuals, vol. 1 Theory, vol. 2 Procedures, vol. 3 Elements, vol. 4 Commands, Swanson Analysis System Inc., DNR300, Houston, USA, 1995.

[36] H.J. Spies, B. Larisch, K. Hock, E. Broszeit, H.J. Schroder, Adhesion and wear resistance of nitrided and TiN coated low alloy steels, Surf. Coatings Technol. 74/75 (1995) 178-182.

[37] J. He, C. Bai, K. Xu, N. Hu, Improving the anticorrosion and mechanical behaviour of PACVD TiN, Surf. Coatings Technol. 74/75 (1995) 387-393.

[38] J. He, K. Xu, N. Hu, Evaluation of bonding strength of thin hard films by spherical rolling test, Surf. Coatings Technol. 97 (1997) 295-298.

[39] J.F. Dill, M.N. Gardos, H.E. Hintermann, H.J. Boving, Rolling Contact Fatigue Evaluation of Hardcoated Bearing steels, ASCE Publication, 1984, pp. 230-240. 
[40] L. Chao, R. Lakshminarayanan, D.K. Shetty, R. Cutler, Rolling contact fatigue and wear of CVD $\mathrm{SiC}$ with residual surface compression, J. Am. Ceram. Soc. 78 (9) (1995) 2307-2313.

[41] B.Y. Sarma, M.M. Mayuram, Some studies on life prediction of thermal sprayed coatings under rolling contact conditions, J. Tribol. 122 (2000) 503-510.

[42] G. Meier zu Kocker, E. Santner, B. Loffelbein, Functional behavior of PVD coatings under sliding and rolling stress conditions, Tribot. J. 4/3 (1998) 241-260.

[43] R. Wei, P.J. Wilbur, F.M. Kustas, A rolling contact fatigue study of hard carbon coated M-50 steel, Trans. ASME 114 (1992) 298-302.
[44] R. Wei, P.J. Wilbur, M. Liston, G. Lux, Rolling contact fatigue wear characteristics of diamond-like carbon coatings on steels, Wear 162 (1993) 558-568.

[45] K. Xu, N. Hu, J. He, Evaluation of the bond strength of hard coatings by the contact fatigue test, J. Adhesion Sci. Technol. 12 (1998) 1055-1069.

[46] A.P. Voskamp, G.E. Hollox, Failsafe rating of ball bearing components, in: J.J.C. Hoo (Ed.), Effects of Steel Manufacturing Process on the Quality of Bearing Steel, ASTM STP 987, ASTM, Philadelphia, PA, 1998, pp. 102-112. 